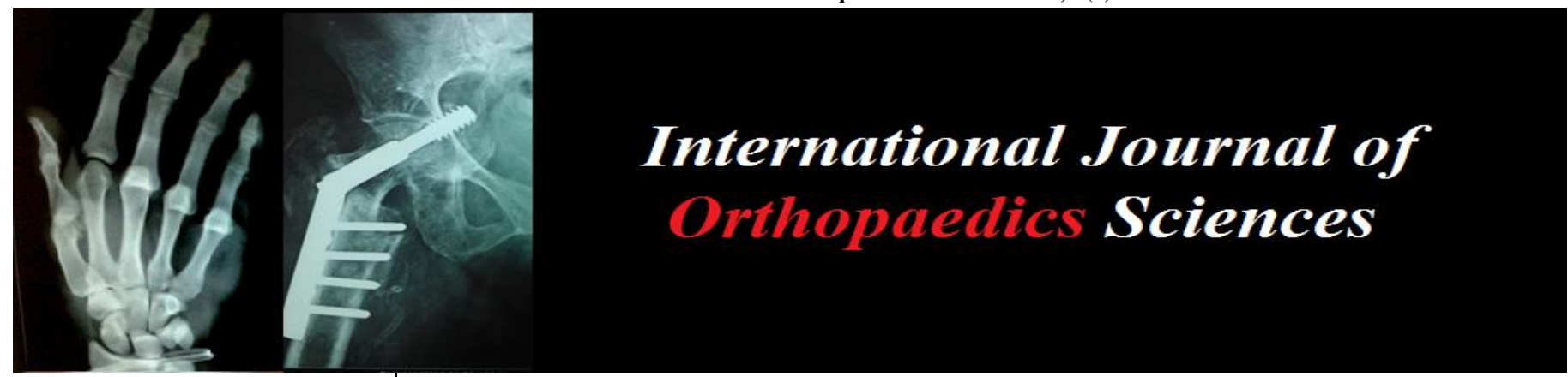

E-ISSN: 2395-1958

P-ISSN: 2706-6630

IJOS 2019; 5(4): 490-493

(C) 2019 IJOS

www.orthopaper.com

Received: 13-08-2019

Accepted: 15-09-2019

Dr. Awadhesh Kumar JR III, SPM Department

KGMU Lucknow, Utter Pradesh, India

Jamal Masood

Professor SPM Department

KGMU Lucknow, Utter Pradesh, India

Corresponding Author: Dr. Awadhesh Kumar JR III, SPM Department KGMU Lucknow, Utter Pradesh, India

\section{Awareness and utilisation of rehabilitative services by person with disability admitted in department of physical medicine and rehabilitation (PMR) King George's medical university (KGMU) Lucknow}

\author{
Dr. Awadhesh Kumar and Jamal Masood
}

DOI: https://doi.org/10.22271/ortho.2019.v5.i4i.1721

Abstract

The present study was undertaken to study the biosocial profile of disabled person admitted in the Department of Physical Medicine and Rehabilitation, King George's Medical University Lucknow Uttar Pradesh.

Aims and Objectives: To study the bio social profile of disabled persons admitted in department of Physical Medicine and Rehabilitation. and to study the knowledge of admitted patients regarding health care services and rehabilitative services available at department of PMR.

Material and Method: A hospital based cross-sectional study was conducted in department of Physical Medicine and Rehabilitation (PMR) KGMU Lucknow City from September 2015 to September 2016. In this study all patients admitted in department of PMR (A total of 102 persons with disability) were interviewed through a pre-designed, pre-tested and semi-structured questionnaire after informed consent. Data analysis was done using SPSS version 21.

Results: About two third $(66.7 \%)$ respondents were aware that facility for calipers and shoes on concession is available for BPL card holders. Whereas one third (31.4\%) were aware that investigation on concession is also available for BPL card holders. Conclusion drawn from observation- About two third $(70.6 \%)$ were male, whereas remaining $(29.4 \%)$ were female, Religion wise proportion of PWD was almost same as in the general population of Hindus (83.3\%) and Muslims (16.7\%). Majority of PWD living in joint family (92.2\%). About half (45.1\%) were illiterate and belong to lower class.

Keywords: Rehabilitation, PWD, PMR KGMU

\section{Introduction}

Any restriction or lack of ability to perform an activity in a manner or within the range considered normal for the human beings, resulting from impairment is termed as disability. Impairment concerns the physical aspects of health; disability is the loss of functional capacity resulting from an impaired organ. Handicap is a measure of the social and cultural consequences of an impairment or disability. The types of disability include loco-motor, paraplegia, cerebral palsy. People with disabilities are more vulnerable than general population to a range of problem including fatigue, depression, and social isolation and have more limited access to health care. Studies showed that persons with disability are less aware about the facility being provided to them in rehabilitation centres so, unable to utilise the facilities meant for them. It is estimated that only $2 \%$ of people with disabilities in developing countries have access to rehabilitation and appropriate basic services. The public health community has traditionally paid little attention to the health needs of people with disabilities. According to WHO, people with disabilities tend to seek more healthcare than people without disabilities. They also have more unmet needs. Recent surveys by WHO indicate that between 76 to $85 \%$ of people with disabilities in developing countries receive no care. The persons with Disabilities (equal opportunities protection of Rights and full participation) Act 1995 (PWD Act) is the landmark legislation for the disabled in India. This is possible only if the concerned person is aware of his rights and knows how to go about it. Therefore, it is necessary to frequently assess the awareness of this act among the disabled and beneficiaries. 
No such study has been conducted in central Uttar Pradesh. The purpose of this study is to understand the awareness and utilization level of health care services and rehabilitation services among people with disabilities.

The present study was conducted with, objectives: To study the bio social profile of disabled persons admitted in department of Physical Medicine and Rehabilitation at a tertiary care hospital, To study the knowledge of admitted patients regarding health care services and rehabilitative services available at department of PMR.. To identify the gaps and to give recommendations to improve health services utilisation by the disabled.

\section{Material and Methods}

Study Setting: The study was conducted in the department of Physical Medicine and Rehabilitation (PMR), King George's Medical University, UP Lucknow.

Study Population: The study population of this study was admitted patients in PMR Department during study period.

Study Design: Hospital based cross sectional study.

Sample size: All the patient admitted in the department of PMR, KGMU Lucknow during the study period i.e. 102.

Inclusion criteria: Patient who are admitted in PMR department and ready to give consent for the study.

Exclusion criteria: Patient who don't give their consent. A pretested semi-structured interview schedule was used to collect necessary information.

Interview schedule: The interview schedule was developed which consists of three sections. The schedule was pretested on a sample of 20, patients from PMR, for the accuracy of responses and to estimate time needed. Something which was confusing or the inconsistent in the pre-test exercise including the interview protocol were corrected before actual data collection. Result of pre-test was not included in final study. The respondents were briefed about the survey in local language. After consent, interview was conducted to fill the schedule.

Ethical Consideration: Verbal consent was taken from each selected participant to confirm willingness. Honest explanation of the survey purpose, description of the benefits and an offer to answer all enquires was made to the respondents. Also affirmation that they are free to withdraw consent and to discontinue participation without any form of prejudice was made Privacy and confidentiality of collected information was ensured throughout the process, Data was collected in a way that makes it impossible or at least very hard to identify the respondent.

\section{Results}

\section{Table-1 Bio-Social Profile of People with Disability (PWD)} $(\mathbf{n}=\mathbf{1 0 2})$

shows that maximum PWD were in the age group 11-30 years $(59.8 \%)$, followed by PWD in the age group less than or equal to 10 years $(27.5 \%)$. The proportion of male PWD $(70.6 \%)$ was more than twice as compared to females (29.4\%). Religion wise proportion of PWD was almost the same as in the general population-Hindu $(83.3 \%)$ and Muslims $(16.7 \%)$.Caste wise distribution shows that maximum PWD belonged to OBC (43.4\%) followed by SC (29.4\%) and general category, $(26.5 \%)$. Majority of PWD were living in joint families $(92.2 \%)$. Distribution on the basis of Education $(41.2 \%)$ are illiterate due to disability whereas, illiterate disable due to other reason (3.9\%), primary school $(23.5 \%)$, middle school $(20.6 \%)$ secondary $(9.8 \%)$ and post graduate 1\%. $23.5 \%$ of PWD are married whereas $(76.5 \%)$ are unmarried. Table-2 shows that the order of awareness among PWD regarding facilities available for them Free diet to admitted patients, Physiotherapy $-84.3 \%$, Free transportation in bus-75.5\%, 3\% reservation in government job $-71.6 \%$, concession inrailways $70 \%$, prosthesis $53.9 \%$, Pension scheme to PWD $52 \%$, orthosis $49 \%$, surgical intervention on concession 49\%, Vocational Training $8.8 \%$, financial assistance $6.8 \%$, Tax relaxation $5.9 \%$, counselling session $2 \%$.Table-3 reveals that about two third $(66.7 \%)$ respondents were aware that facility for callipers and shoes on concession is available for BPL card holders. Whereas one third (31.4\%) were aware that investigation on concession is also available for BPL card holders. Only $(18.6 \%)$ were aware that surgery on concession is also available. Observation among PWD for awareness of BPL facilities shows that only $31.4 \%$ aware that there is concession on investigation rest $68.6 \%$ came to know about this facility after filling of the survey form.18.6\% of PWD knows that concession on surgery available rest 84.4 percent have no knowledge about the same.66.7\% PWD are aware that there is concession on callipers and shoe.

\section{Discussion}

Srivastava et al. studied physically disabled people of the rural population of district Mau in Uttar Pradesh and they found that most prevalent physical disability was locomotor 10.44 per thousand.

It was observed in the present study that many barrier faced by PWD in day to day life like entry to park and malls $78.4 \%$, transporatation $75.5 \%$, construction and building ramp related $60.78 \%$, not helping attitude of people towards PWD $11.76 \%$. We could not find any other studies for comparing other literature. Distribution of PWD on the basis awareness among PWD regarding facilities available for them is ${ }^{[1]}$ free diet to admitted patients $-92.2 \%$

${ }^{[2]}$ physiotherapy $-84.3 \%{ }^{[3]}$ free transportation in bus- $75.5 \%{ }^{[4]}$ $3 \%$ reservation in government job $71.6 \%$ [5] concession in railways $70 \%{ }^{[6]}$ prosthesis $53.9 \%{ }^{[7]}$ pension scheme to PWD $52 \%{ }^{[8]}$ orthothesis $49 \%{ }^{[9]}$ surgical intervention on concession $49 \%{ }^{[10]}$ vocational Training $8.8 \%{ }^{[11]}$ financial assistance $6.8 \%{ }^{[12]}$ tax relaxation $5.9 \%{ }^{[13]}$ counselling session $2 \%$.

Vijay Kumar and Singh (2004) studied awareness among 36 PWD attending PMR, OPD at AIIMS, New Delhi. They found that PWD All of them were aware about travel concession, awareness regarding other facilities were preferential land allotment $(30.55 \%), 3 \%$ reservation in government job (27.77\%), unemployment allowance, $(16.66 \%)$, insurance scheme $(11.11 \%)$, income tax rebate $8.33 \%$, free education till 18 years, scheme for aids and appliances $5.5 \%$, relaxation of upper age limit health and safety measure at job, free books and uniform $(2.77 \%)$. 
Table 1: Bio-Social Profile of People with Disability (PWD) $(n=102)$

\begin{tabular}{|c|c|c|c|}
\hline \multicolumn{2}{|c|}{ Bio-Social Characteristics } & No & $\%$ \\
\hline \multirow{4}{*}{$\begin{array}{c}\text { Age } \\
\text { (years) }\end{array}$} & $\leq 10$ & 28 & 27.5 \\
\hline & $11-30$ & 61 & 59.8 \\
\hline & $31-50$ & 10 & 9.8 \\
\hline & $\geq 51$ & 03 & 2.9 \\
\hline \multirow{2}{*}{ Gender } & Male & 72 & 70.6 \\
\hline & Female & 30 & 29.4 \\
\hline \multirow{2}{*}{ Religion } & Hindu & 85 & 83.3 \\
\hline & Muslim & 17 & 16.7 \\
\hline \multirow{4}{*}{ Caste } & General & 27 & 26.5 \\
\hline & $\mathrm{SC}$ & 30 & 29.4 \\
\hline & ST & 1 & 1.0 \\
\hline & $\mathrm{OBC}$ & 44 & 43.1 \\
\hline \multirow{4}{*}{ Type of Family } & Joint & 94 & 92.2 \\
\hline & Nuclear & 05 & 4.9 \\
\hline & Single & 02 & 2.0 \\
\hline & Second generation & 01 & 1.0 \\
\hline \multirow{8}{*}{ Education } & Illiterate because of disability & 42 & 41.2 \\
\hline & Illiterate because of other reasons & 04 & 3.9 \\
\hline & Primary School & 24 & 23.5 \\
\hline & Middle School & 21 & 20.6 \\
\hline & High School & 00 & 00 \\
\hline & Secondary & 10 & 9.8 \\
\hline & Graduate & 00 & 00 \\
\hline & Post Graduate & 1 & 1 \\
\hline \multirow{2}{*}{ Marital status } & Married & 24 & 23.5 \\
\hline & Unmarried & 78 & 76.5 \\
\hline
\end{tabular}

Table 2: Awareness among PWD about the facilities available ( $\mathrm{n}=102)$

\begin{tabular}{|c|c|c|}
\hline Awareness & $\mathbf{N}$ & $\%$ \\
\hline \multicolumn{3}{|c|}{ Physiotherapy } \\
\hline Yes & 86 & 84.3 \\
\hline No & 16 & 15.7 \\
\hline \multicolumn{3}{|c|}{ Prosthesis } \\
\hline Yes & 55 & 53.9 \\
\hline No & 47 & 46.1 \\
\hline \multicolumn{3}{|c|}{ Orthosis } \\
\hline Yes & 50 & 49.0 \\
\hline No & 52 & 51.0 \\
\hline \multicolumn{3}{|c|}{ Surgical intervention on concession } \\
\hline Yes & 50 & 49.0 \\
\hline No & 52 & 51.0 \\
\hline \multicolumn{3}{|c|}{ Free diet to admitted patient } \\
\hline Yes & 94 & 92.2 \\
\hline No & 08 & 7.8 \\
\hline \multicolumn{3}{|c|}{ Vocational training } \\
\hline Yes & 09 & 8.8 \\
\hline No & 93 & 91.2 \\
\hline \multicolumn{3}{|c|}{ Physiotherapy session } \\
\hline Yes & 86 & 84.3 \\
\hline No & 16 & 15.7 \\
\hline \multicolumn{3}{|c|}{ Counselling session } \\
\hline Yes & 2 & 2.0 \\
\hline No & 100 & 98.0 \\
\hline \multicolumn{3}{|c|}{ Tax relaxation } \\
\hline Yes & 6 & 5.9 \\
\hline No & 96 & 94.1 \\
\hline \multicolumn{3}{|c|}{ Financial assistance } \\
\hline Yes & 7 & 6.8 \\
\hline No & 95 & 93.1 \\
\hline \multicolumn{3}{|c|}{ Pension Scheme to PWD } \\
\hline Yes & 53 & 52.0 \\
\hline No & 49 & 48.0 \\
\hline \multicolumn{3}{|c|}{ Free transportation in bus } \\
\hline Yes & 77 & 75.5 \\
\hline No & 25 & 24.5 \\
\hline Concession in rai & & \\
\hline
\end{tabular}




\begin{tabular}{|c|c|c|}
\hline Yes & 72 & 70.6 \\
\hline No & 30 & 29.4 \\
\hline 3\% Reservation in Government job & & \\
\hline Yes & 73 & 71.6 \\
\hline No & 29 & 28.4 \\
\hline
\end{tabular}

Table 3: Awareness among PWD regarding facilities for BPL card holders.

\begin{tabular}{|c|c|c|}
\hline Awareness & N & \% \\
\hline Investigation on concession & & \\
\hline Yes & 32 & 31.4 \\
\hline No & 70 & 68.6 \\
\hline Surgery on concession & & \\
\hline Yes & 19 & 18.6 \\
\hline No & 83 & 81.4 \\
\hline Callipers and shoes on concession & & \\
\hline Yes & 68 & 66.7 \\
\hline No & 34 & 33.3 \\
\hline
\end{tabular}

\section{Conclusion}

Present study shows that about two third (66.7\%) respondents were aware that facility for callipers and are free available for BPL card holders. whereas one third $(31.4 \%)$ were aware that investigation is free available for BPL card holders. Only $(18.6 \%)$ were aware that surgery on concession is also available. The present study was conducted at PMR (Physical Medicine and Rehabilitation centre) KGMU, Lucknow. In this study, 102 people with disability (PWD) who were admitted in PMR department during the period September 2015 to October 2016 were included. About two third $(70.6 \%)$ were male, whereas remaining $(29.4 \%)$ were female. Religion wise proportion of PWD was almost same as in the general population of Hindus $(83.3 \%)$ and Muslims (16.7\%). Majority of PWD living in joint family (92.2\%). About half $(45.1 \%)$ were illiterate and belong to lower class. All PWD has orthopaedic disability and about half $(54.9 \%)$ of them had acquired it by road traffic accident. Only $2 \%$ utilize counselling service and had undergone psychological counseling. 92.2\%, PWD patients were aware about free diet to admitted patients. Loss of work is a critical, undesirable situation. The study data show that the severely disabled tend to be more interested in rehabilitation services than persons with less incapacitating disabilities. A greater proportion of men received services, possibly because of their greater labour force obligations. In present study 102 patients were interviewed admitted in study centre Physical Medicine and Rehabilitation, (PMR) KGMU Lucknow. In this study we concluded that most of patients belong to low socio economic status, below poverty line and illiterate their poverty is so much that they cannot even earn to fulfil their basic needs and demand of life. Some of patients are so much satisfied with PMR department that they wish to stay there as long they are allowed.

\section{References}

1. Lollar DJ. Public Health and Disability: Emerging Opportunities. Public Health Rep. 2002; 117:131-6.

2. World Health Organization. Training in the community for people with disabilities. Geneva: WHO, 1989.

3. Havercamp SM, Scandlin D, Roth M. Health disparities among adult with developmental disabilities, adults with other disabilities, and adult not reporting disability in North Carolina. Public Health Rep. 2004; 119:418-26.

4. Pal HR, Saxena S, Chandrashekar K, Sudha SJ, Murty $\mathrm{RS}$, Thara $\mathrm{R}$ et al. Issues related to disability in India: A focus group study. Nat Med J India. 2000; 13:237-41.
5. Williams MH, Bowie C. Evidence of unmet need in the care of severely physically disabled adults. BMJ. 1993; 306:95-8.

6. Patel SK, Ladusingh L. Age pattern of onset of disability and treatment seeking behaviour of disabled persons in India. XXVI IUSSP International Population Conference. Available from: URL: http://iussp2009.princeton.edu/abstracts/91173

7. Hosain GM, Chatterjee N. Health care utilization by disabled persons: A survey in rural Bangladesh. Disabil Rehabil. 1998; 20:337-45.

8. D'Noveymony MA, Raj SS. A study in the family and socio-economic conditions of the persons with disabilities in Vallioor Panchayat Union. Asian Pac Disabil Rehabil J. 2003; 5:14-20.

9. Chopra A, Saluja M, Patil J, Tandale HS. Pain and disability, perceptions and beliefs of a rural Indian population: A WHO- ILAR COPCORD study. WHOInternational League of Associations for Rheumatology. Community Oriented Program for Control of Rheumatic Diseases. J Rheumatol. 2002; 29:614-21.

10. Abidi J. Current status of employment of disabled people in Indian industries. http://www.dinf.ne.jp/doc/english/asia/resource/apdrj/ z13jo0400/z13jo0410.html. 